\title{
MENDOBRAK POLA KONVENSIONAL PENGEMBANGAN KEWIRAUSAHAAN DI ERA INDUSTRI 4.0: PENINGKATAN PERANAN PERGURUAN TINGGI MELALUI INKUBATOR BISNIS DAN TEKNOLOGI
}

\author{
M. Ariza Eka Yusendra ${ }^{1}$, Melda Agarina ${ }^{2 *}$, Susanti $^{3}$, Hendra Kurniawan ${ }^{4}$, Lilla Rahmawati ${ }^{3}$, \\ Niken Paramitasari ${ }^{5}$ \\ 1,2,3,4,5 Institut Informatika dan Bisnis Darmajaya
}

arizaeka@darmajaya.ac.id, agharina@darmajaya.ac.id, susanti@darmajaya.ac.id, Hendra.kurniawan@darmajaya.ac.id, lillakeling@darmajaya.ac.id

\begin{abstract}
Abstrak
Untuk bersaing dan bertahan di era industri 4.0, setiap pelaku usaha harus mampu mengembangkan model bisnis yang kontemporer berbasis digital agar meraih efisiensi yang tinggi dan kualitas produk yang baik. Akan tetapi, masih banyak stakeholder pengembang usaha yang masih menjalankan sistem secara konvensional, sehingga model bisnis yang dijalankan belum tentu dapat beradaptasi dengan lingkungan bisnis 4.0. Kesenjangan tersebut dapat dijembatani melalui pelibatan perguruan tinggi sebagai agen perubah dan sumber pengetahuan untuk memperbesar tingkat hidup dari para pelaku usaha, terutama sekali usaha mikro, kecil dan menengah. Tujuan dari kegiatan pengabdian kepada masyarakat ini adalah untuk meningkatkan peranan perguruan tinggi dalam pengembangan dunia kewirausahaan melalui lembaga inkubator bisnis dan teknologi dengan menerapkan Integrated Incubation System based on creative economy dengan mengambil kasus di Perguruan Tinggi IIB Darmajaya. Metode yang digunakan adalah kombinasi dari kegiatan observasi, wawancara, konsultasi, pelatihan, workshop, mentoring dan coaching, untuk memanfaatkan teknologi baru dan internet yang sejalan dengan industri 4.0. Mitra kegiatan pengabdian adalah para pelaku usaha yang berasal dari beberapa segmen yaitu: pengusaha kuliner, teknologi tepat guna, digital startupreneur hingga sivitas akademika mahasiswa. Hasil dari kegiatan pengabdian ini para mitra mampu mengembangkan model bisnis baru yang dapat bersaing di industri 4.0, peningkatan produksi, penjualan, profit dan skala usaha.
\end{abstract}

Kata Kunci : Industri 4.0, Kewirausahaan, Inkubator Bisnis, Integrated Incubation System, IIB Darmajaya 


\title{
BREAKING THE PATTERNS OF CONVENTIONAL ENTREPRENEURSHIP DEVELOPMENT IN 4.0 INDUSTRY: BOOSTING HIGHER EDUCATION ROLE THROUGH BUSINESS INCUBATOR AND TECHNOLOGY
}

\author{
M. Ariza Eka Yusendra ${ }^{1}$, Melda Agarina ${ }^{2 *}$, Susanti ${ }^{3}$, Hendra Kurniawan ${ }^{4}$, Lilla Rahmawati ${ }^{3}$, \\ Niken Paramitasari ${ }^{5}$ \\ 1,2,3,4,5 Institut Informatika dan Bisnis Darmajaya
}

arizaeka@darmajaya.ac.id, agharina@darmajaya.ac.id, susanti@darmajaya.ac.id, Hendra.kurniawan@darmajaya.ac.id, lillakeling@darmajaya.ac.id

\begin{abstract}
To compete and survive in the 4.0 industry era, everyone in business must be able to develop contemporary, digital based business models to achieve the highest level of efficiency and the best quality of products. However, many stakeholders still choose to go the conventional way with business models that are not designed to adapt to 4.0 business environment. The solution to this gap could possibly be higher education involvement as agents of change and knowledge resource to upgrade micro, small, and medium enterprises. The purpose of this community service programme was to do just that through business incubator organisations and technology by implementing Integrated Incubation System based on creative economy on cases in IBI Darmajaya. The method used was a combination of observation, interview, consultation, workshop, mentoring, coaching, and utilising new technologies. This community service programme involved partners from various business segments such as culinary entrepreneurs, appropriate technology, digital startupreneur, and student academics. This programme resulted in the partners' newfound skill of developing contemporary business models for 4.0 industry and an increase in production, sales, profit, and business scale.
\end{abstract}

Keywords: 4.0 Industry, Entrepreneurship, Business Incubator, Integrated Incubation System, IBI Darmajaya

\section{PENDAHULUAN}

Indonesia saat ini telah bersiap untuk menyambut dan memasuki era industri 4.0. Segenap pihak yang terlibat, mulai dari kalangan pemerintahan, swasta dan berbagai elemen pendukung lainnya sudah mulai mengantisipasi dengan menyiapkan berbagai upaya yang diperlukan (Kadir, 2018). Salah satunya adalah bagaimana mempersiapkan dunia bisnis dan kewirausahaan di Indonesia dalam menyambut era yang sangat didominasi oleh integrasi teknologi digital dan internet tersebut, karena sektor ini yang menerima dampak besar dari revolusi industri 4.0 (Huizingh, 2017).
Dengan berbagai kemudahan komunikasi antar manusia dan manusia dengan mesin melalui internet, membuat semua entitas didalam sistem industri tidak lagi dibatasi ruang dan waktu (Luu \& Ngo, 2018). Hal ini membuat revolusi industri 4.0 berpengaruh pada cara industri beroperasi dan melayani konsumennya. Suka atau tidak suka semua industri dalam bisnis harus beradaptasi. Ukuran besar perusahaan tidak lagi menjadi jaminan, namun kelincahan perusahaan menjadi kunci keberhasilan meraih prestasi dengan cepat (van Doorn, Heyden, \& Volberda, 2017). Dunia kewirausahaan di Indonesia telah membuktikan hal tersebut dimana Gojek, Bukalapak, Traveloka dan Tokopedia sebagai pemain baru dikancah bisnis mampu menggulingkan pemain-pemain utama bisnis yang lama, yang tidak

Ekonomi, Sosial dan Budaya

1314 
hanya besar dalam ukuran perusahaan akan tetapi memiliki penguasaan pasar yang dominan pada zamannya. Dapat dikatakan industri 4.0 mengakibatkan persaingan menjadi semakin intensif, kompetitif dan disruptif. Model bisnis baru harus diciptakan untuk menciptakan nilai yang luar biasa bagi konsumen di generasi keempat, dan model bisnis yang lama akan lambat laun menjadi usang dan punah (García-Villaverde, Rodrigo-Alarcón, Parra-Requena, \& Ruiz-Ortega, 2018). Analisis situasi umum diatas mengimplikasikan bahwa dunia kewirausahaan di Indonesia - yang mana didominasi oleh generasi muda milenial, memiliki kesempatan yang besar untuk berperan aktif sebagai game changer dengan pengetahuan dan pemahamannya terhadap teknologi digital, internet, big data dan artificial intelligence (Gümüsay \& Bohné, 2018).

Walaupun potensi besar yang ditawarkan oleh era industri 4.0 secara jelas dapat dilihat, akan tetapi tidak banyak para wirausahawan di Indonesia yang berusaha secara cepat dan taktis menyesuaikan model bisnis perusahaannya dengan perkembangan trend industri 4.0 (Ismail et al., 2015). Hal ini diakibatkan walaupun era telah berganti, sistem pengembangan yang diterapkan kepada dunia kewirausahaan oleh stakeholder pengembang kewirausahaan masih menggunakan cara yang konvensional (McAdam, Miller, \& McAdam, 2016). Beruntung bagi para pelaku wirausaha yang ada di kota besar dimana atmosfer industri 4.0 telah terbentuk sehingga pengembangan bisnisnya menjadi lebih adaptif dengan perkembangan zaman. Akan tetapi keberuntungan yang serupa belum tentu ditemui di daerah-daerah terutama sekali di pedesaan (Sung, 2015). Memang benar pemerintah telah mengeluarkan kebijakan insentif yang besar untuk dapat mendorong penciptaan wirausaha-wirausaha baru di daerah - berupa program hibah dan pinjaman lunak melalui dinas koperasi, perdagangan ataupun bekraf, hanya saja pemanfaatannya belum maksimal untuk menghantarkan bisnis ke kancah persaingan industri 4.0. Dapat dikatakan beberapa entitas stakeholder pengembang kewirausahaan dan pelaku bisnis wirausaha mengalami gegar pengetahuan dan tidak mengetahui peta jalan untuk memasuki area bisnis di industri 4.0. Karena itu, Perguruan Tinggi perlu dilibatkan sebagai salah satu agen perubah yang akan menghubungkan dan memberikan solusi pengetahuan dan keterampilan di daerah - beberapa masalah yang identik juga dialami oleh industri UKM/UMKM di perkotaan, untuk memanfaatkan potensi besar dari industri 4.0 (Dalmarco, Hulsink, \& Blois, 2018). Salah satu solusi yang bisa dihadirkan untuk mengatasi masalah gegar pengetahuan dan sesat jalan ke industri 4.0 para pelaku wirausaha adalah dengan memperkenalkannya pada Inkubator Bisnis dan Teknologi Perguruan Tinggi.

Inkubator Bisnis dan Teknologi Perguruan Tinggi merupakan organisasi di Perguruan Tinggi yang memiliki tugas untuk mempercepat pertumbuhan dan keberhasilan perusahaan tahap awal melalui penyediaan layanan bisnis yang terintegrasi. Secara umum ada empat layanan yang disediakan oleh Inkubator Bisnis dan Teknologi yaitu yaitu: (1) Infrastructures Provider-menyediakan suatu ruang sharing bersama yang dapat dimanfaatkan untuk pengembangan economies of scale, seperti: ruang kantor, meeting rooms, fasilitas lab, internet, dan lainnya (Hong, Yang, Wang, Zhou, \& Deng, 2018). (2) business services - menyediakan layanan pengembangan bisnis seperti: konsultasi strategi, riset pasar, pelatihan keuangan. Pelatihan penggunaan teknologi dan internet, hingga registrasi merek ataupun lisensi. Tujuan dari layanan ini adalah membantu proses pengembangan manajemen suatu bisnis (van Weele, van Rijnsoever, \& Nauta, 2017). (3) Financing Provider \& Facilitization menyediakan atau mampu bekerjasama dengan pihak penyedia keuangan dan permodalan. Tujuannya adalah untuk memberikan leverage bagi bisnis rintisan untuk dapat mendapatkan pembiayaan pengembangan bisnis (Wright, 2017) dan (4) People Connectivity - berisikan layanan mentoring, coaching, interaksi dengan wirausahawan lainnya atau lebih jauh lagi adalah penyediaan koneksi ke pasar (Newman, Obschonka, Schwarz, Cohen, \& Nielsen, 2018).

Keempat layanan diatas dipadu dengan pengetahuan Perguruan Tinggi akan industri 4.0, ketersediaan pakar dan tenaga ahli serta rantai kerjasama yang luas dengan pihak akademik, industri, pemerintah dan masyarakat, diharapkan Inkubator Bisnis dan Teknologi Perguruan Tinggi dapat membentuk suatu model pengembangan kewirausahaan yang adaptif dengan volatilitas industri 4.0 (González-Serrano, Valantine, Hervás, Pérez-Campos, \& Moreno, Ekonomi, Sosial dan Budaya

1315 
2018). Berbeda dengan pendekatan pengembangan kewirausahaan yang konvensional dan cenderung setiap stakeholdernya bergerak sporadis, Inkubator Bisnis dan Teknologi Perguruan Tinggi dapat mengintegrasikan berbagai pihak mulai dari akademik, pemerintah, swasta, perbankan hingga komunitas usaha agar bergerak bersama dalam memajukan dunia kewirausahaan baik didalam lingkungan perguruan tinggi itu sendiri ataupun di lingkungan masyarakat (Gümüsay \& Bohné, 2018). Tujuan akhirnya adalah bagaimana menghantarkan suatu perusahaan pemula dapat survive di era industri 4.0, memiliki kinerja bisnis yang tinggi dan melakukan scale-up menjadi perusahaan yang beroperasi skala nasional ataupun internasional (Madichie \& Gbadamosi, 2017).

Institut Informatika dan Bisnis Darmajaya, merupakan salah satu perguruan tinggi swasta di Provinsi Lampung yang sangat memperhatikan dalam pengembangan kewirausahaan nasional. Keseriusan dari perguruan tinggi ini diejawantahkan melalui pendirian Inkubator Bisnis dan Teknologi IIB Darmajaya (INKUBITEK IIB Darmajaya) yang menjadi ujung tombak dalam pengembangan atmosfer kewirausahaan di kampusnya. Saat ini INKUBITEK IIB Darmajaya telah memiliki 10 tenant yang berasal dari berbagai kalangan dan berhasil mendapatkan beberapa pembiayaan modal untuk kemudian disalurkan kepada para tenantnya setelah melalui proses inkubasi. Tentunya beberapa keberhasilan INKUBITEK IIB Darmajaya tidak tercipta dengan cepat akan tetapi melalui proses panjang dan mulai ekstensif pada saat Perguruan Tinggi ini mendapatkan hibah pengabdian kepada masyarakat PPK (Program Pengembangan Kewirausahaan).

Karena itu, paper ini berusaha untuk menceritakan kegiatan pengabdian kepada masyarakat yang fokus pada pengembangan kewirausahaan melalui
Inkubator Bisnis dan Teknologi Perguruan Tinggi dengan mengambil studi kasus dari INKUBITEK IIB Darmajaya. Artikel ini akan menjelaskan model, metode dan pendekatan hingga kegiatan-kegiatan inkubator bisnis dan teknologi yang applicable untuk digunakan mengembangkan perusahaan-perusahaan pemula berbasis teknologi tidak hanya di internal Perguruan Tinggi, akan tetapi juga di lingkungan masyarakat. Diharapkan kegiatan-kegiatan pengembangan melalui inkubator bisnis dan teknologi ini memberikan inspirasi dan menggerakkan perguruan tinggi lainnya untuk berkontribusi dalam penyiapan UKM/UMKM/wirausaha awal.

\section{METODE}

Kegiatan pengembangan kewirausahaan melalui inkubator bisnis dan teknologi perguruan tinggi ini memiliki dua kegiatan. Yang pertama adalah pemberdayaan fungsi dari Inkubator Bisnis dan Teknologi - yang dalam hal ini mengambil kasus di INKUBITEK IIB Darmajaya dan yang kedua adalah melalui inkubator bisnis yang telah berdaya, lembaga ini mampu menginkubasi dan mendampingi perusahaan tahap awal, UKM/UMKM dan atau para sivitas akademika yang ingin berwirausaha. Metode pelaksanaan kegiatan bervariatif, mulai dari observasi, wawancara, pembahasan strategis dengan pihak-pihak stakeholder kewirausahaan internal perguruan tinggi maupun eksternal, pengadaan pelatihan dan workshop hingga melakukan kerjasama dengan pihak eksternal. Secara garis besar kegiatan Program Pengembangan Kewirausahaan diarahkan untuk mengimplementasikan model operasional pengembangan atmosfer kewirausahaan melalui inkubator bisnis dan teknologi seperti pada gambar 1. 


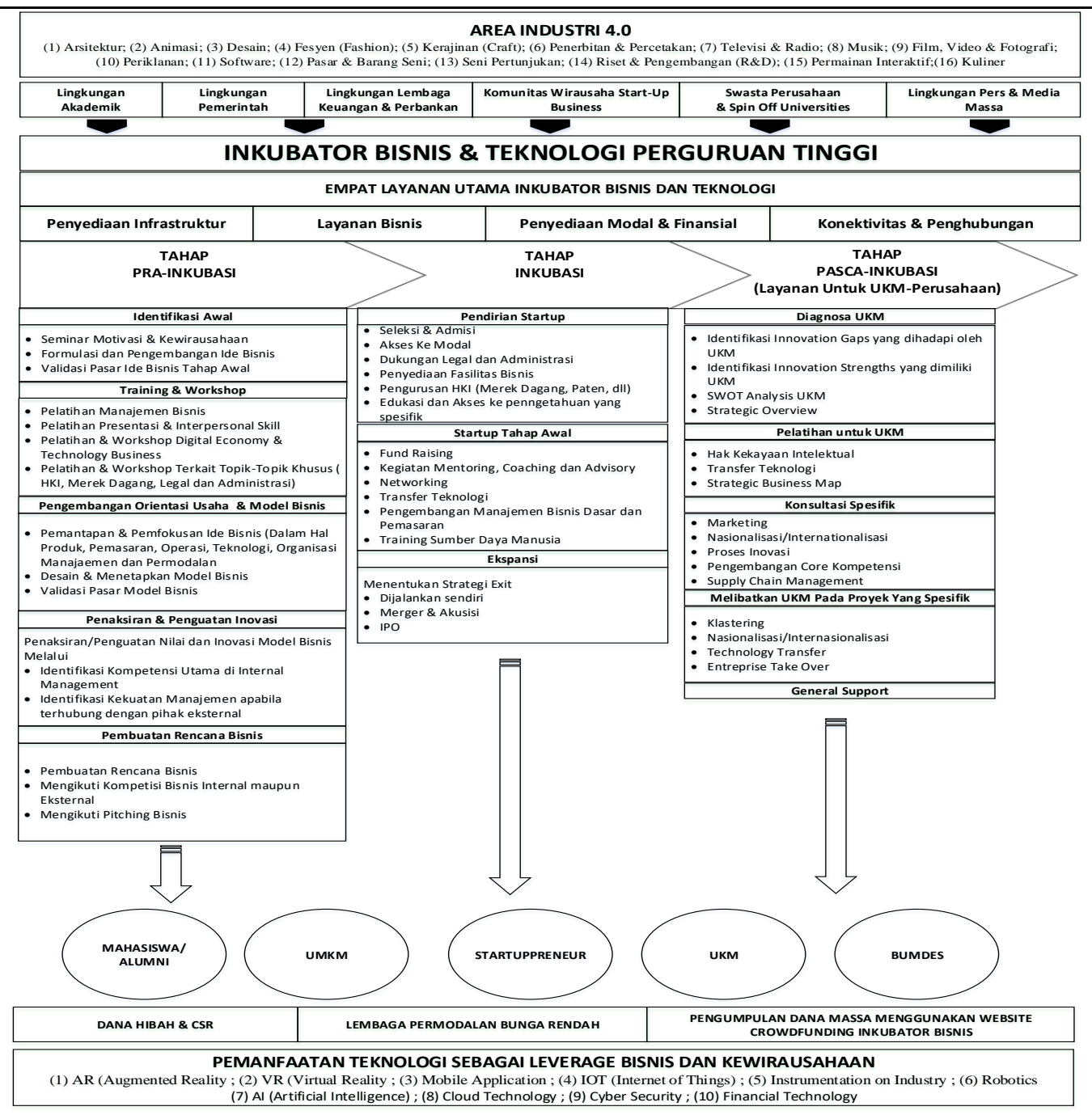

\section{Gambar 1. Model Operasional Inkubator Bisnis dan Teknologi Perguruan Tinggi}

Gambar 1 menunjukkan model operasional Inkubator Bisnis dan Teknologi yang diimplementasikan di INKUBITEK IIB Darmajaya. Pada bagian awal inkubator bisnis dan teknologi perlu menentukan area industri 4.0 yang akan dilayani, dimana terdiri dari 16 subsektor ekonomi kreatif yang saat ini sedang menjadi trend pengembangan di industri 4.0. Tentu saja untuk melayani ke-16 subsektor industri tersebut Inkubator Bisnis dan Teknologi tidak dapat bekerja sendiri, akan tetapi perlu menjalin kerjasama dengan berbagai stakeholder pengembang kewirausahaan yang terdiri dari: (1) Dunia akademik, (2) Dinasdinas pemerintahan yang bertanggung jawab pada pengembangan usaha, (3) Industri perbankan dan keuangan, (4) Komunitas wirausaha, (5) Perusahaan swasta dan spinoff dari perguruan tinggi sebagai mitra, (6) Industri pers dan media. Inkubator Bisnis juga diarahkan untuk fokus pada empat layanan utama yaitu: (1) Penyediaan infrastruktur, (2) Pengadaan layanan bisnis, (3) Penyediaan modal dan finansial, dan (4) Konektivitas dan penghubungan antar pihak dalam dunia kewirausahaan. Layanan ini diperuntukkan tidak hanya untuk sivitas akademika perguruan tinggi, akan tetapi dapat diekspansi ke lingkungan luar, yaitu masyarakat startupreneur, UKM, UMKM dan BUMDES.

Kegiatan pengembangan dan inkubasi kewirausahaan terdiri dari 3 tahapan yaitu PraInkubasi, Inkubasi dan Pasca-Inkubasi, dimana masing-masing kegiatan memiliki detil kegiatan

$$
\text { Ekonomi, Sosial dan Budaya }
$$


yang rinci dalam usahanya mempercepat pertumbuhan dan meningkatkan kinerja mitra Inkubator Bisnis dan Teknologi. Lebih lanjut semua layanan dan kegiatan inkubasi didukung dengan teknologi informasi dan komunikasi yang menjadi dasar era industri 4.0 - dimana IIB Darmajaya yang merupakan institut bisnis dan informatika - melalui INKUBITEK IIB Darmajaya mendasarkan diri pada 10 teknologi industri 4.0 yaitu: Augmented Reality (AR), Virtual Reality (VR), Mobile Application, Internet of Things (IoT), Instrumentation, Robotika, Artificial Technology, Cloud Computing, Cyber Security dan Financial Technology. Akhirnya untuk dapat membiayai kegiatan-kegiatan diatas sebuah Inkubator Bisnis dan Teknologi dapat bekerjasama dengan stakeholder luar untuk mendapatkan pembiayaan dari dana hibah dan CSR, pemodalan dari lembaga keuangan, pengumpulan dana crowdfunding, hingga bagi hasil dengan pihak mitra bisnis.

\section{HASIL DAN PEMBAHASAN}

\subsection{Pengembangan \& Pemberdayaan Inkubator Bisnis dan Teknologi Perguruan Tinggi}

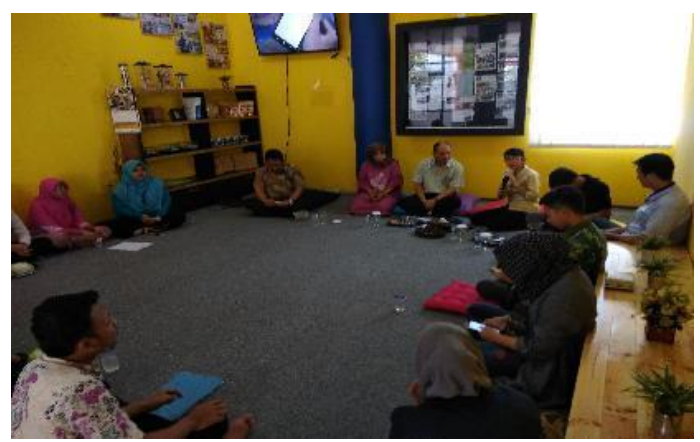

Untuk dapat menciptakan atmosfer dan orientasi kewirausahaan baik di lingkungan akademik maupun di masyarakat, Inkubator Bisnis dan Teknologi Perguruan Tinggi perlu didesain dan diberdayakan melalui beberapa kegiatan pengembangan manajamen terlebih dahulu. Kegiatan pengembangan didasarkan pada model operasional seperti yang ditunjukkan pada gambar 1. Langkah awal yang dilakukan oleh tim pengabdian kepada masyarakat adalah melakukan kegiatan Pelatihan dan Workshop Manajamen Tata Kelola Inkubator Bisnis - studi kasus INKUBITEK IIB Darmajaya berikut dengan dosen-dosen kewirusahaan yang menjadi mitra INKUBITEK IIB Darmajaya. Kegiatan Pelatihan dan workshop ini memberikan pengetahuan dan rancang bangun layanan inkubator bisnis dan teknologi yang terkait dengan 4 layanan utama: (1) Infrastructure Provider, (2) Business Services, (3) Financial Provider dan (4) People Connectivity. Selain itu juga, pada saat pelatihan pengelola juga diberikan pengetahuan bagaimana seharusnya organisasi Inkubator Bisnis didesain. Pengetahuan untuk melakukan inkubasi tenant juga diberikan pada tahap ini berikut juga stakeholderstakeholder yang perlu diajak untuk bekerjasama.

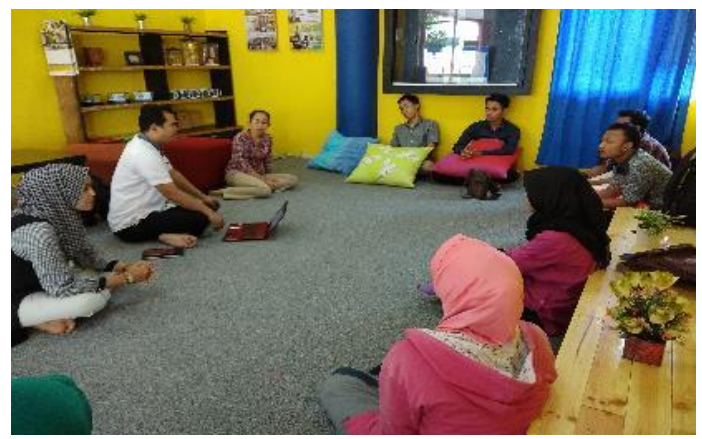

Gambar 2. Workshop \& Pelatihan Manajemen Tata Kelola Inkubator Bisnis

Selain manajemen tata kelola, INKUBITEK IIB Darmajaya juga diberikan pelatihan dan workshop untuk mengembangkan model bisnis menggunakan Smart Business Map dan Business Model Canvas. Pengetahuan dan Keahlian dalam pengembangan model bisnis mutlak dikuasai oleh INKUBITEK IIB Darmajaya karena nantinya akan mendampingi para mitranya untuk mendesain model bisnis yang adaptif dengan industri 4.0 - dimana sangat berbeda dengan model bisnis konvensional yang telah berkembang. Pelatihan dan workshop Smart Business Map dan Business Model Canvas ini diadakan dengan bekerjasama dengan UNILA dan Yayasan OIM Pro Indonesia, untuk mendapatkan insight eksternal yang lebih komprehensif terkait dengan lanskap model bisnis yang tengah dan akan menjadi trend. 

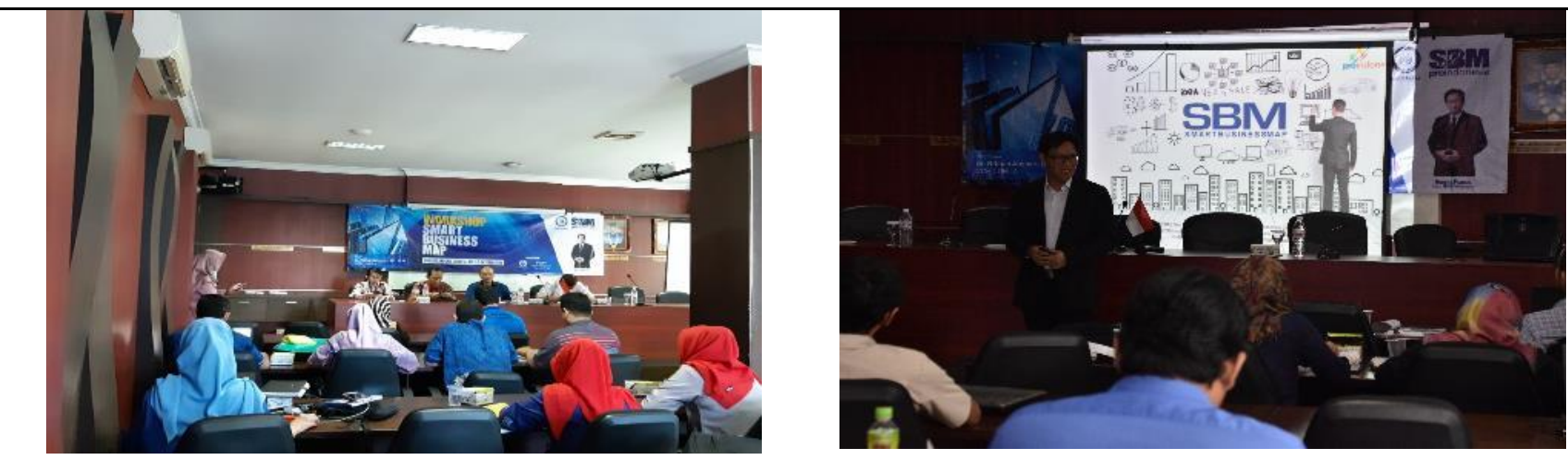

Gambar 3. Pelatihan dan Workshop Model Bisnis Untuk Inkubator Bisnis dan Teknologi IIB Darmajaya

Kegiatan pengembangan dan pemberdayaan tidak hanya cukup pada kegiatan pelatihan dan workshop saja. Untuk melengkapi pelatihan manajemen tata kelola Inkubator Bisnis dan Desain Model Bisnis, INKUBITEK IIB Darmajaya difasilitasi untuk melakukan kegiatan studi banding ke beberapa Inkubator Bisnis Perguruan Tinggi seperti BINUS University, Universitas Multimedia Nusantara dan

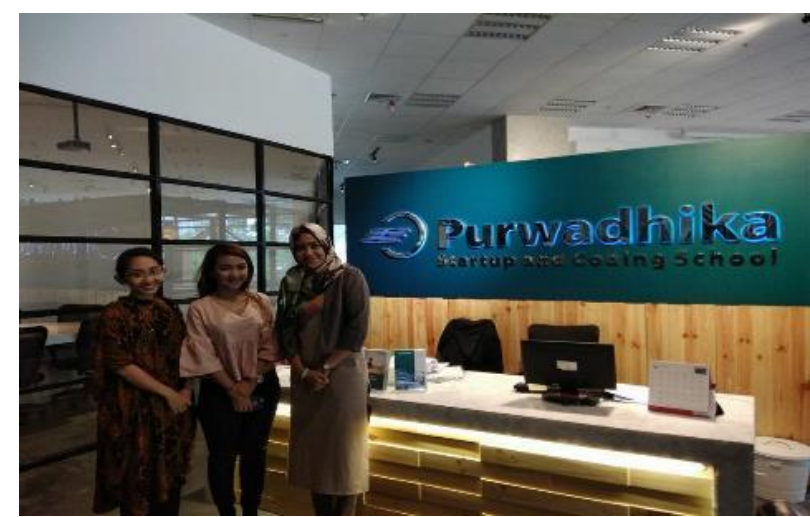

Purwadhika Startup \& Coding School. Kegiatan ini dilakukan untuk menambah wawasan tentang bagaimana Inkubator Bisnis dan Teknologi harus dijalankan, membanding berbagai macam faktor yang perlu disiapkan agar layanan Inkubator Bisnis dapat terselenggara, hingga menimba pengalaman melalui sharing dengan inkubator bisnis perguruan tinggi yang telah lebih dahulu berjalan.

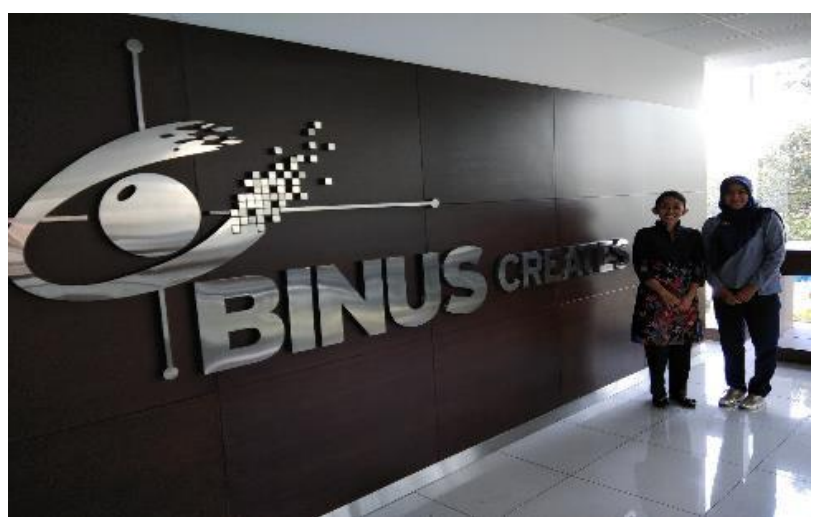

Gambar 4. Studi Banding ke Inkubator Bisnis dan Teknologi Perguruan Tinggi Eksternal

Kegiatan pengembangan kewirausahaan tidak bisa dilakukan secara sendiri oleh suatu lembaga. Oleh karenanya INKUBITEK IIB Darmajaya melakukan inisiasi penjalinan kerjasama dengan stakeholder luar seperti dinas-dinas pemerintahan yang berkaitan dengan pengembangan usaha dan industri, perusahaan-perusahaan swasta, lembaga perbankan dan keuangan, komunitas wirausaha seperti TDA Chapter Lampung dan Krakatau Digital Movement, hingga media massa. Tidak mudah untuk melakukan kerjasama dengan berbagai macam pihak stakeholder tersebut. Karenanya strategi yang dijalankan oleh INKUBITEK IIB Darmajaya untuk membina hubungan baik dengan stakeholder adalah dengan menyelenggarakan kegiatan pelatihan dari lembaga tersebut kepada dosen dan mahasiswa wirausaha kampus IIB Darmajaya. Diharapkan dengan adanya pelatihan tersebut, akan terjalin hubungan yang harmonis dan saling membutuhkan dari kedua pihak sekaligus memberikan landasan untuk kerjasama-kerjasama berikutnya di masa depan. 

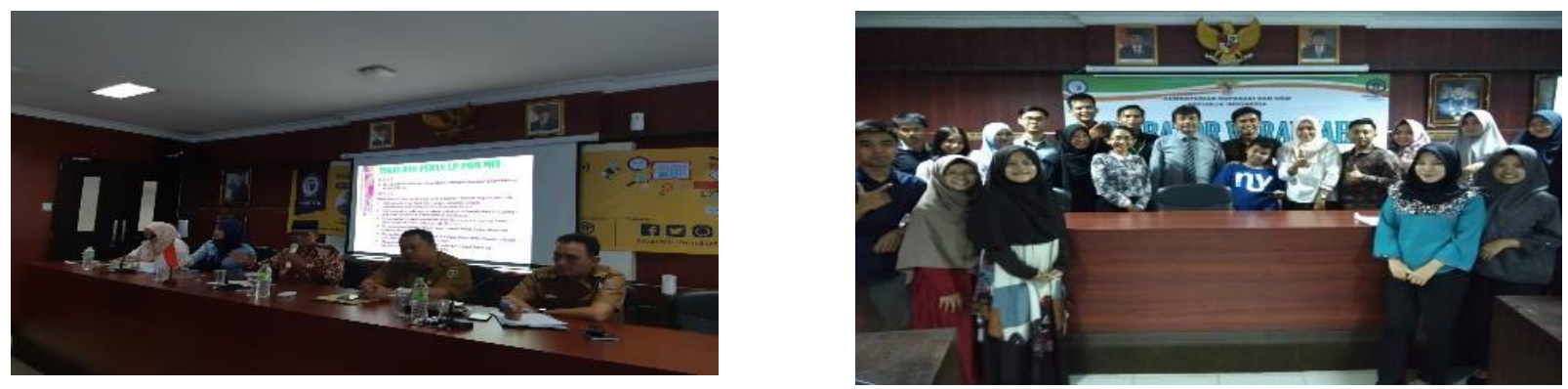

Gambar 5. Kerjasama Dengan Stakeholder Melalui Strategi Pelatihan

Setelah melewati kegiatan pelatihan, workshop, studi banding dan kerjasama. Tim pengabdian kepada masyarakat, tim pengelola INKUBITEK IIB Darmajaya dan dosen-dosen kewirausahaan melakukan koordinasi. Kegiatan koordinasi ini dimaksudkan untuk membentuk model bisnis dan arah kegiatan Inkubator Bisnis dan Teknologi. Pada tahap ini semua keperluan manajemen dan model pengembangan bisnis startup telah berhasil disosialisasikan sehingga Inkubator Bisnis dan Teknologi siap melakukan operasi. Hasil akhir dari kegiatan pengembangan dan pemberdayaan Inkubator Bisnis dan Teknologi adalah tersusunnya program-program inkubasi, jaringan kerjasama dengan stakeholder pengembang wirausaha yang kuat, dan terbentuknya KPI (Key Performance Indicator) sebagai alat ukur kinerja INKUBITEK IIB Darmajaya.

\subsection{Pengembangan Atmosfer dan Orientasi Kewirausahaan di Kampus IIB Darmajaya.}

Setelah Inkubator Bisnis dan Teknologi (INKUBITEK) IIB Darmajaya telah siap untuk melaksanakan kegiatan layanan inkubasinya, program awal yang menjadi fokus utamanya adalah melakukan pengembangan atmosfer dan orientasi kewirausahaan di lingkungan akademik kampus IIB Darmajaya. Kegiatan pengembangan atmosfer dan orientasi kewirausahaan kampus IIB Darmajaya dilaksanakan melalui kerjasama dengan dosen-dosen peraih hibah PPK dan PPUPIK dari kemenristekdikti. Skema kerjasama yang dibentuk melalui program-program pengabdian kepada masyarakat ini adalah dengan mengintegrasikan program dan kegiatan pengabdian kepada masyarakat berbasis kewirausahaan tersebut dengan layanan dan kegiatan-kegiatan inkubasi yang diadakan oleh INKUBITEK IIB Darmajaya. Selain mendapatkan bantuan dari skema pengabdian PPK dan PPUPIK, INKUBITEK IIB Darmajaya juga mendapatkan bantuan yang cukup signifikan dari institusi Perguruan Tinggi IIB Darmajaya komitmen kampus IIB Darmajaya akan membantu operasional kegiatan sebesar Rp.100.000.000/tahun.

Kegiatan layanan dan proses inkubasi dari INKUBITEK IIB Darmajaya direalisasikan dalam program tahunan "Darmajaya Startup Competition" (DSC) yang merupakan ajang kompetisi wirausaha khusus internal IIB Darmajaya untuk menjaring calon-calon wirausaha bisnis startup dari kalangan mahasiswa dan alumni IIB Darmajaya. Berdasarkan model operasional Inkubator Bisnis dan Teknologi Perguruan Tinggi yang menjadi dasar pengembangan kewirausahaan, tipe kegiatan pengembangannya berada pada tahapan PraInkubasi. Intinya kegiatan Pra-Inkubasi adalah bagaimana mahasiswa dapat termotivasi untuk membuat startup, mampu men-generate idea bisnis yang sesuai dengan lingkungan industri 4.0, mampu membuat model bisnis yang menguntungkan, terampil dalam membuat rencana bisnis dan mau mengikuti pitching dalam usahanya mengembangkan bisnis hingga merealisasikan bisnisnya untuk dapat dioperasikan. Kegiatan DSC ini juga melibatkan kelas-kelas mata kuliah dan dosen-dosen kewirausahaan untuk dapat menjaring wirausaha muda. Oleh karena kegiatan DSC ini melibatkan banyak entitas didalamnya - kegiatan pengabdian kepada masyarakat, perkuliahan akademik dan kemahasiswaan, maka INKUBITEK IIB Darmajaya melakukan kerjasama dengan berbagai pihak seperti: Lembaga Penelitian dan Pengabdian Kepada Masyarakat IIB Darmajaya, Tim Dosen Kewirausahaan, Himpunan Mahasiswa IIB Darmajaya, Bagian Kemahasiswaan IIB Darmajaya hingga Pusat Pelatihan IIB Darmajaya.

$$
\text { Ekonomi, Sosial dan Budaya }
$$




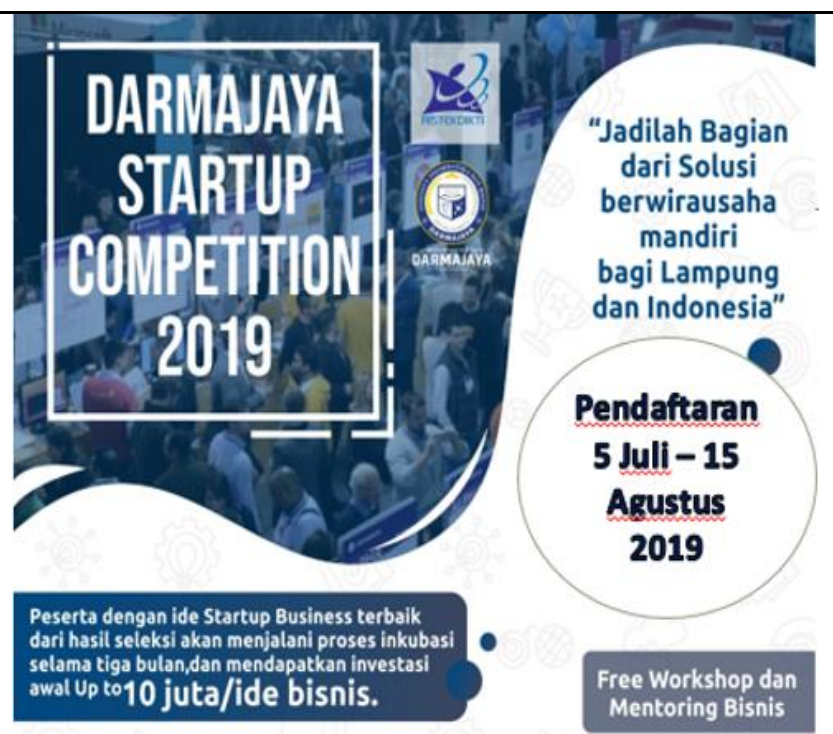

Gambar 6. Pengumuman Kegiatan Darmajaya Startup Competition 2019

Kegiatan Darmajaya Startup Competition ini beraneka ragam mulai dari pengadaan seminar motivasi wirausaha, success story para startup muda, ngoprek IT, Game dan IoT, pelatihan dan workshop design thinking, pembuatan model business canvas,

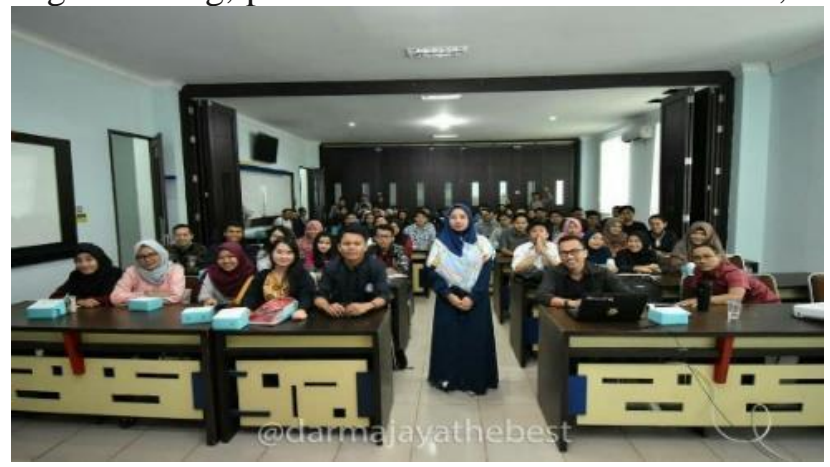

(a) Seminar Motivasi Kewirausahaan

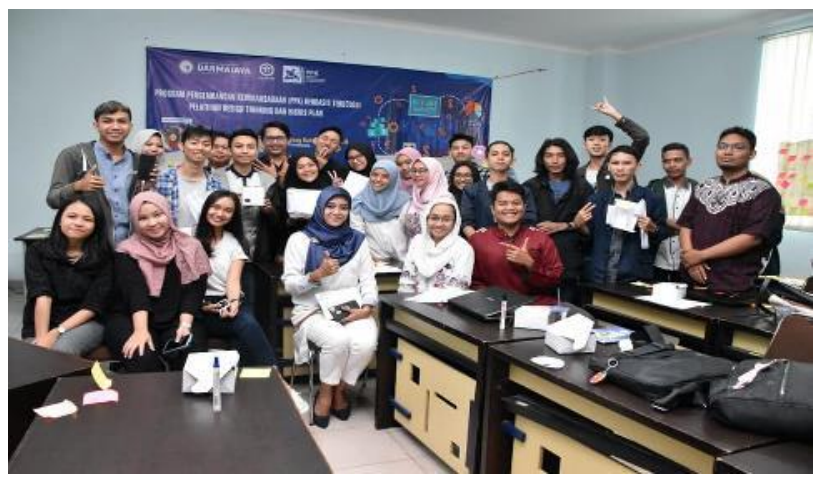

(c) Pelatihan Design Thinking personal building untuk menginisiasi usaha hingga pitching untuk memperoleh dana pendampingan tenant startup yang akan dibina oleh INKUBITEK IIB Darmajaya.

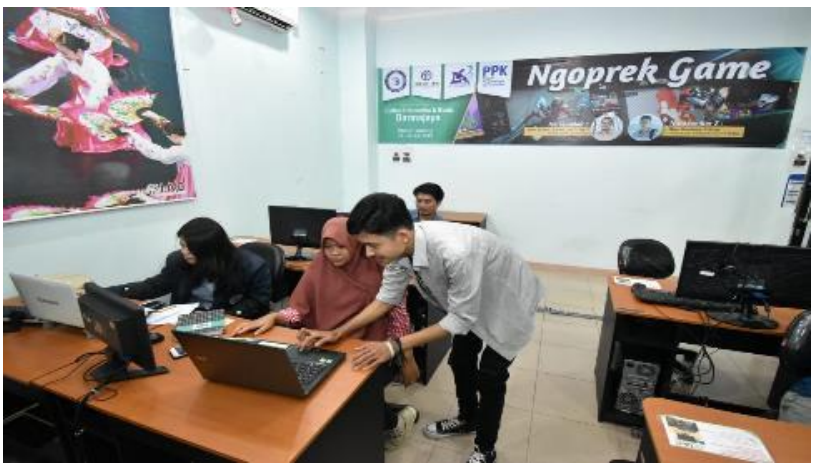

(b) Ngoprek IT, Game dan IoT

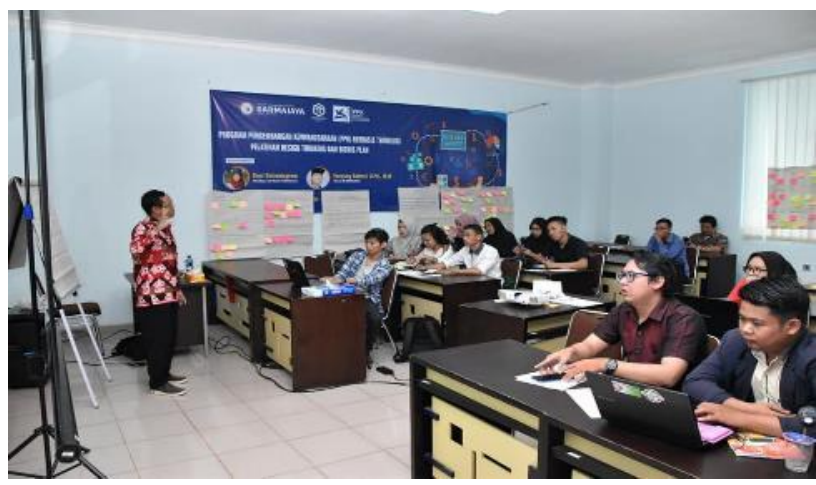

(d) Pelatihan Business Plan dan Business Model

Ekonomi, Sosial dan Budaya 


\section{Gambar 7. Kegiatan Darmajaya Startup Competition IIB Darmajaya 2019}

Program DSC (Darmajaya Startup Competition) ternyata sangat diapresiasi secara positif dari mahasiswa dan alumni yang mengikuti kegiatan tersebut. Terbukti kurang lebih ada 100 mahasiswa yang berpartisipasi dalam program - dari berbagai macam jurusan dan program studi, dengan 80 ide bisnis yang diajukan. Dari ke 80 ide bisnis tersebut
INKUBITEK IIB Darmajaya melakukan seleksi menjadi 20 rencana bisnis yang diikutkan dalam tahap pitching untuk menerima dana pendampingan usaha. Hasil pitching didapatkan 5 ide dan rencana bisnis yang akan dikawal oleh INKUBITEK IIB Darmajaya untuk masuk ke tahap inkubasi, yaitu:

Tabel 1. Tenant DSC yang akan dibina INKUBITEK IIB Darmajaya

\begin{tabular}{|c|c|c|c|c|}
\hline No & Nama & Ide Bisnis & Keterangan Bisnis & Area Bisnis \\
\hline 1. & Gusti Christiawan & Ngekost & $\begin{array}{l}\text { Merupakan platform aplikasi yang } \\
\text { menyediakan layanan informasi } \\
\text { kos-kosan }\end{array}$ & Mobile Aplication \\
\hline 2. & Denny Prastiawan & Sensor Rumah Pintar & $\begin{array}{l}\text { Merupakan instrumen IoT yang } \\
\text { berfungsi sebagai pengamanan } \\
\text { rumah apabila ditinggalkan oleh } \\
\text { pemiliknya }\end{array}$ & $\begin{array}{l}\text { IoT (Internet of } \\
\text { Things) }\end{array}$ \\
\hline 3. & $\begin{array}{ll}\text { Sheni } & \text { Mega } \\
\text { Winanda } & \end{array}$ & Marie & $\begin{array}{lr}\text { Aplikasi yang mempertemukan } \\
\text { vendor pernikahan dengan calon } \\
\text { pengantin yang } \\
\text { menyelenggarakan } \\
\text { pernikahan } & \text { pesta } \\
& \end{array}$ & Mobile Aplication \\
\hline 4. & Yosianus Antonio & $\begin{array}{l}\text { Codink } \quad \text { (Coding } \\
\text { Kids) }\end{array}$ & $\begin{array}{l}\text { Aplikasi yang menyediakan } \\
\text { layanan user khusus anak-anak } \\
\text { untuk belajar pemrograman } \\
\text { melalui game online }\end{array}$ & Edutech \\
\hline 5. & Aji Kartika & Sehatkuy & $\begin{array}{l}\text { Aplikasi Online yang membantu } \\
\text { masyarakat untuk mengetahui } \\
\text { informasi tentang penyakit yang } \\
\text { dideritanya }\end{array}$ & Mobile Application \\
\hline
\end{tabular}

\subsection{Pengembangan Kewirausahaan di Luar Perguruan Tinggi (Eksternal)}

Kegiatan pengembangan kewirausahaan INKUBITEK IIB Darmajaya tidak hanya dilaksanakan di dalam lingkungan kampus IIB Darmajaya saja, akan tetapi dapat diperluas ke lingkungan masyarakat luar. Pada tahun 2019, INKUBITEK IIB Darmajaya mengajukan diri untuk mendapatkan pembiayaan PPBT (Perusahaan Pemula Berbasis Teknologi) dan berhasil menjadi wakil Provinsi Lampung satu-satunya yang menerima hibah PPBT. Konsekuensi dari keikutsertaan INKUBITEK IIB Darmajaya dalam PPBT adalah kesempatannya mendampingi tenanttenant dari luar.

Pada saat melaksanakan kegiatan PPBT dan mendampingi tenant-tenant eksternal, kegiatan kewirausahaan yang dilakukan difokuskan pada kegiatan Tahap Inkubasi sesuai dengan Model Operasional Inkubator Bisnis dan Teknologi Perguruan Tinggi pada Gambar 1. Kegiatan inkubasi

$$
\text { Ekonomi, Sosial dan Budaya }
$$


ini difokuskan pada pengembangan startup tahap awal dan membantu tenant untuk melakukan ekspansi. Inisiatif pendampingan lebih ditekankan pada fund raising, melaksanakan kegiatan mentoring, coaching dan advisory, pengembangan promosi dan networking, transfer teknologi, training sumber daya manusia, dukungan legal dan administrasi perijinan dan pengurusan HKI (Merek dagang dan paten). Hal ini dikarenakan tenant-tenant yang menjadi mitra INKUBITEK IIB Darmajaya, bisnisnya sudah berjalan akan tetapi membutuhkan pengembangan teknis untuk melakukan scale-up. Beberapa tenant yang menjadi mitra adalah sebagai berikut:

Tabel 2. Tenant Eksternal Inkubator Bisnis Dan Teknologi IIB Darmajaya

\begin{tabular}{|l|l|l|c|}
\hline No & \multicolumn{1}{|c|}{ Nama Perusahaan } & \multicolumn{1}{|c|}{ Deskripsi Usaha } & Lokasi \\
\hline 1. & Sanedu & $\begin{array}{l}\text { Sanedu adalah aplikasi pembelajaran secara } \\
\text { online, berbasis website dan android yang } \\
\text { diperuntukkan bagi pelajar SD, SMP dan SMA }\end{array}$ & Bandar Lampung \\
\hline 2. & Angsur & $\begin{array}{l}\text { Angsur merupakan perusahaan rintisan Islamic } \\
\text { Financial Technology (Fintech) berbasis syariah } \\
\text { yang membantu mahasiswa dalam memenuhi } \\
\text { kebutuhan dalam berbelanja secara daring di } \\
\text { situs e-commerce }\end{array}$ & Bandar Lampung \\
\hline 3. & Tekila Soap & $\begin{array}{l}\text { Tekila Soap memproduksi Banana Peel Vita } \\
\text { Soap yang merupakan sabun herbal terbuat dari } \\
\text { ekstrak alkali kulit pisang dan bahan-bahan alami } \\
\text { lainnya }\end{array}$ & Bandar Lampung \\
\hline 4. & H-Fish (Healthy Fish) & $\begin{array}{l}\text { H-Fish merupakan produk suplemen organik dan } \\
\text { pakan ikan yang mampu mempercepat umur } \\
\text { panen dari ikan air tawar, khususnya ikan lele }\end{array}$ & Tulang Bawang Barat \\
\hline 5. & Emping Jagung Ainun & $\begin{array}{l}\text { Emping Jagung Ainun memproduksi makanan } \\
\text { ringan dari bahan baku jagung jenis hibdrida } \\
\text { pilihan sebagai sumber protein dan karbohidrat } \\
\text { melalui proses mekanisasi mesin pemipihan }\end{array}$ & Pesawaran \\
\hline
\end{tabular}

Dapat dilihat pada tabel 2, tenant eksternal INKUBITEK IIB Darmajaya berasal dari industri yang berbeda-beda. Oleh karenanya perlakuan dan pemberian pendampingan juga berbeda sesuai dengan kebutuhan dari tenant. Untuk Tenant Sanedu, INKUBITEK IIB Darmajaya melakukan pendampingan berupa digital marketing, pengembangan official web, online promotion untuk meningkatkan jumlah user, legalitas usaha, pelatihan pembuatan UI-UX website dan aplikasi, pelatihan Smart Business Map dan keuangan hingga pengembangan sumber daya manusia. Setelah melalui proses inkubasi, tenant Sanedu mampu memperoleh 10.523 user, jumlah omset sebesar
Rp.213.945.000/bulan, jumlah tenaga kerja sebanyak 24 karyawan dan telah berbadan usaha PT (Perseroan Terbatas).

Tenant Angsur oleh INKUBITEK IIB Darmajaya diberikan pelatihan data sains dan fintech, manajemen keuangan dan pengelolaan sumber daya manusia. Selain pelatihan, tenant Angsur juga dibantu kegiatan promosi dan pemasarannya melalui online dan offline berupa mengikuti kegiatan pameran BUMN Kreatif. INKUBITEK IIB Darmajaya juga membantu remodeling bisnis Angsur dengan cara menambah rekanan marketplace, redesign aplikasi web dan mobile, dan

$$
\text { Ekonomi, Sosial dan Budaya }
$$


penciptaan traffic user agar bersedia menggunakan jasa layanan keuangan online mereka. Saat ini Angsur masih berada dalam inkubasi INKUBITEK IIB Darmajaya dan memiliki kinerja omset Rp.37.500.000/bulan, +/- 500 transaksi/bulan dan memiliki 7 karyawan.

Tenant Tekila Soap diberikan pendampingan umum oleh INKUBITEK IIB Darmajaya seperti pengujian laboratorium, validasi produk, pengurusan legalitas BPOM, pembuatan database pelanggan, pelatihan manajemen operasi dan produksi sekaligus pembuatan SOP dan KPI Manajemen. Selain itu juga tenant Tekila Soap juga diuruskan perijinan produksinya melalui Dinas Kesehatan Lampung untuk produk kosmetik dan didaftarkan merek dagangnya ke ditjen HKI. Pelatihan manajemen keuangan, Smart Business Map dan pengembangan sumber daya manusia juga disertakan dalam paket pendampingan inkubasi. Hingga saat ini kinerja bisnis dari Tekila Soap cukup baik dengan menghasilkan +/- Rp.40.000.000/ bulannya dan jumlah karyawan sebanyak 7 orang.

Tenant H-Fish diberikan layanan oleh INKUBITEK IIB Darmajaya berupa pelatihan manajemen operasi

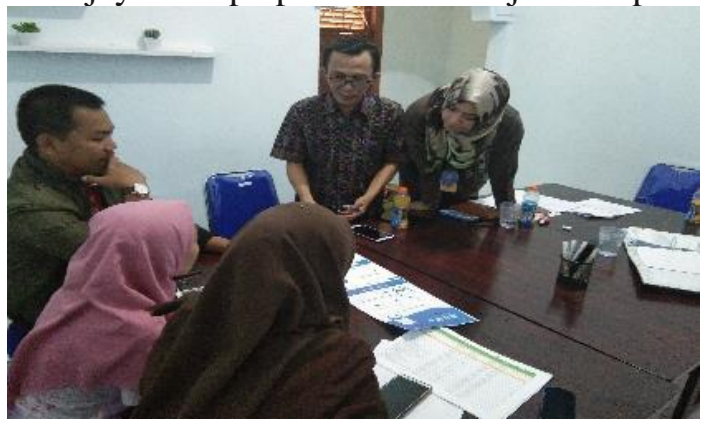

(a) Pendampingan Sanedu

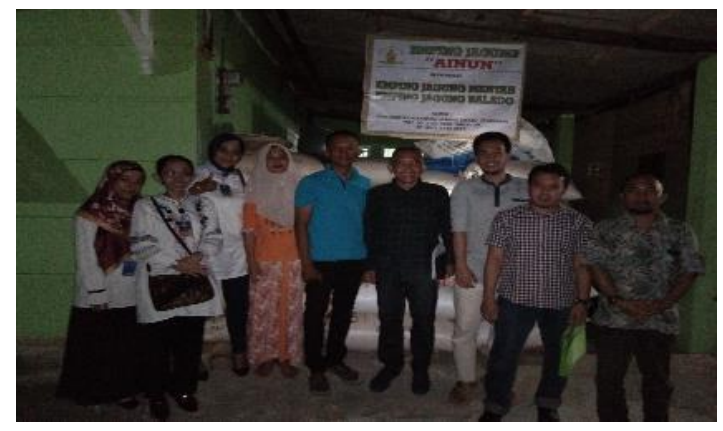

(c) Pendampingan Emping Jagung Ainun dan produksi, penyediaan alat sarana dan prasarana produksi, pendampingan legalitas usaha, pembuatan database pelanggan, perluasan pasar melalui pemasaran offline dan social media marketing, serta pengurusan ijin edar. Diharapkan H-Fish akan dapat memproduksi pakan dan suplemen ikan sebanyak 20 ton perbulan dengan realisasi pendapatan Rp.218.500.000, memiliki legalitas badan usaha dan merek yang terdaftar di ditjen HKI. Untuk Emping Jagung Ainun dilakukan pendampingan inkubasi melalui pelatihan manajemen keuangan, legalitas usaha, pengembangan rencana bisnis untuk mendapatkan tambahan modal, pembenahan layout produksi, pelatihan manajemen operasi dan produksi dan perluasan pemasaran melalui strategi offline dan online. Dari hasil inkubasi yang telah dilalui, emping jagung Ainum memiliki performa yang bagus pula dimana usaha ini mampu memproduksi emping jagung sebanyak 12 ton/bulan dengan jumlah omset sebesar Rp.88.200.000/bulan. Saat ini emping jagung Ainun telah memiliki CV, SIUPP, TDP dan HO sehingga memungkinkan untuk melakukan pengembangan bisnis secara lebih luas - misalnya masuk ke pasar ritel modern.

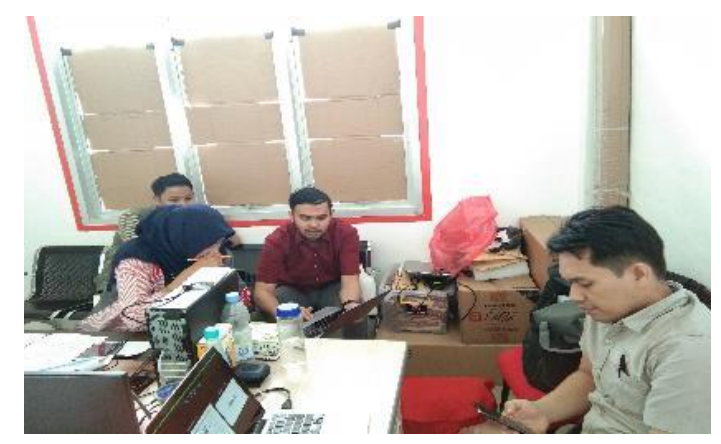

(b) Pendampingan Angsur

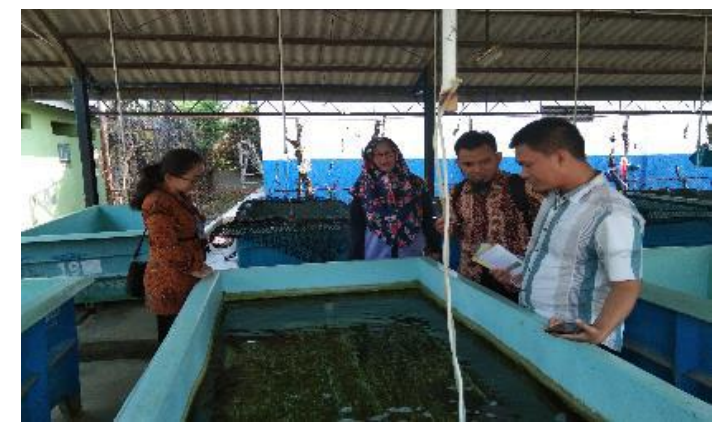

(d) Pendampingan H-Fish

Gambar 8. Kegiatan Inkubasi Tenant-Tenant Eksternal INKUBITEK IIB Darmajaya

Ekonomi, Sosial dan Budaya 
Pada tahap inkubasi setiap tenant eksternal diberikan KPI (Key Performance Indicator) yang akan dievaluasi setiap bulan, semester dan tahunan. Setiap kegiatan diharapkan untuk dapat mencapai KPI yang telah ditetapkan sehingga dapat dilihat kemajuan daripada kegiatan inkubasi yang telah dilakukan. Apabila target KPI para tenant telah tercapai maka, ke-lima startup bisnis tersebut dapat melakukan scale-up dan berpindah ke Tahap Pasca Inkubasi, yang lebih berfokus pada perluasan pasar ke kancah nasional ataupun internasional. Hingga saat ini, kelima tenant masih berada tahap inkubasi karena ada beberapa kinerja bisnis yang perlu diperbaiki dan KPI yang harus dicapai.

\section{KESIMPULAN DAN SARAN}

Pendekatan pengembangan kewirausahaan dan pemberdayaan masyarakat secara konvensional tidak bisa lagi dijalankan pada era industri 4.0. Tidak bisa setiap stakeholder berjalan sendiri-sendiri dalam pengembangan kewirausahaan, karena akan memberikan solusi parsial terhadap permasalahan bisnis wirausaha. Stakeholder pengembang wirausaha tidak bisa bertumpu pada model bisnis yang lama, karena preferensi konsumen milenial telah berubah signifikan. Kegiatan pengabdian kepada masyarakat juga tidak bisa hanya dilakukan secara individu dan sporadis oleh perguruan tinggi akan tetapi harus integratif antara satu skema dengan skema yang lainnya dan fokus pada peningkatan kesejahteraan dan pembentukan masyarakat yang mandiri. Tidak hanya itu setiap pihak harus secara progresif memanfaatkan teknologi digital dan internet sebagai pendukung dan fondasi utama karena merupakan kebutuhan bisnis, pemberdayaan masyarakat dan kewirausahaan utama di masa depan. Inkubator Bisnis dan Teknologi Perguruan Tinggi dapat menjadi solusi yang praktis untuk menjawab tantangan yang ditawarkan oleh perkembangan industri 4.0.

Model Operasional Inkubator Bisnis dan Teknologi yang dikembangkan oleh tim pengabdian kepada masyarakat IIB Darmajaya dapat digunakan sebagai landasan pengembangan kewirausahaan dengan menggunakan Inkubator Bisnis dan Teknologi Perguruan Tinggi. Melalui model operasional tersebut, inkubator bisnis dan teknologi dapat secara lincah berperan untuk merealisasikan 16 subsektor industri ekonomi kreatif 4.0, melakukan inisiasi kerjasama dengan berbagai macam stakeholder pengembang kewirausahaan internal dan eksternal perguruan tinggi, hingga kejelasan layanan dan kegiatan inkubasi yang dapat disesuaikan dengan kebutuhan mitra bisnis berdasarkan tahapan yang sudah mereka lalui. Tidak hanya itu, inkubator bisnis dan teknologi terutama sekali Perguruan Tinggi yang berbasiskan teknologi informasi dan komunikasi mampu mendasarkan pada 10 sektor teknologi yang menjadi backbone industri 4.0 sehingga dapat menghantarkan para pebisnis awal untuk mengadaptasikan bisnisnya dengan teknologi digital dan internet. Layanan Inkubator Bisnis dan Teknologi Perguruan Tinggi tidak hanya bisa diakses di lingkungan akademik akan tetapi juga dapat diimplementasikan kepada lingkungan diluar seperti apa yang sudah dicontohkan oleh INKUBITEK IIB Darmajaya. Sinergitas kegiatan, pengetahuan, keterampilan, dan pelaku bisnis inilah yang menjadi kekuatan Inkubator Bisnis dan Teknologi Perguruan Tinggi untuk dapat memajukan dunia kewirausahaan dan pemberdayaan masyarakat yang berkelanjutan di Indonesia.

Model pengembangan Inkubator Bisnis dan Teknologi Perguruan Tinggi dibentuk dengan memanfaatkan kompetensi Perguruan Tinggi yang berbasiskan teknologi. Tim pengabdian IIB Darmajaya sadar, bahwa ada beberapa perguruan tinggi yang tidak berbasiskan teknologi, akan tetapi memiliki keinginan untuk membentuk inkubator bisnisnya sendiri. Karena itu disarankan bagi perguruan-perguruan tinggi yang tidak berbasiskan teknologi untuk dapat berkolaborasi dengan perguruan tinggi yang berbasiskan teknologi dalam bentuk kerjasama strategis untuk mendapatkan transfer teknologi dan perluasan wawasan pengembangan akan dunia kewirausahaan era industri 4.0 .

\section{REFERENSI}

Dalmarco, G., Hulsink, W., \& Blois, G. V. (2018). Creating entrepreneurial universities in an emerging economy: Evidence from Brazil.

Ekonomi, Sosial dan Budaya

1325 
Technological Forecasting and Social Change. doi:10.1016/j.techfore.2018.04.015

García-Villaverde, P. M., Rodrigo-Alarcón, J., Parra-Requena, G., \& Ruiz-Ortega, M. J. (2018). Technological dynamism and entrepreneurial orientation: The heterogeneous effects of social capital. Journal of Business Research, 83, 51-64. doi:10.1016/j.jbusres.2017.10.004

González-Serrano, M. H., Valantine, I., Hervás, J. C., Pérez-Campos, C., \& Moreno, F. C. (2018). Sports university education and entrepreneurial intentions. Education + Training, 60(5), 389405. doi:10.1108/et-12-2017-0205

Gümüsay, A. A., \& Bohné, T. M. (2018). Individual and organizational inhibitors to the development of entrepreneurial competencies in universities. Research Policy, 47(2), 363-378. doi:10.1016/j.respol.2017.11.008

Hong, J., Yang, Y., Wang, H., Zhou, Y., \& Deng, P. (2018). Incubator interdependence and incubation performance in China's transition economy: the moderating roles of incubator ownership and strategy. Technology Analysis \& Strategic Management, 1-15. doi:10.1080/09537325.2018.1487551

Huizingh, E. K. R. E. (2017). Moving the innovation horizon in Asia. Technovation, 60-61, 43-44. doi:10.1016/j.technovation.2017.01.005

Ismail, K., Anuar, M. A., Omar, W. Z. W., Aziz, A. A., Seohod, K., \& Akhtar, C. S. (2015). Entrepreneurial Intention, Entrepreneurial Orientation of Faculty and Students towards Commercialization. Procedia - Social and Behavioral Sciences, 181, 349-355. doi:10.1016/j.sbspro.2015.04.897

Kadir, N. (2018). Analysis of entrepreneurship perception and business developmental strategy of silk in Wajo Regency, South Sulawesi, Indonesia. International Journal of Law and Management, $\quad 60(1), \quad$ 102-113. doi:10.1108/ijlma-11-2016-0114

Luu, N., \& Ngo, L. V. (2018). Entrepreneurial orientation and social ties in transitional economies. Long Range Planning. doi:10.1016/j.lrp.2018.04.001

Madichie, N. O., \& Gbadamosi, A. (2017). The entrepreneurial university: an exploration of "value-creation" in a non-management department. Journal of Management Development, 36(2), 196-216. doi:10.1108/jmd06-2016-0098

McAdam, M., Miller, K., \& McAdam, R. (2016). Situated regional university incubation: A multi-level stakeholder perspective. Technovation, 50-51, 69-78. doi:10.1016/j.technovation.2015.09.002

Newman, A., Obschonka, M., Schwarz, S., Cohen, M., \& Nielsen, I. (2018). Entrepreneurial selfefficacy: A systematic review of the literature on its antecedents and outcomes, and an agenda for future research. Journal of Vocational Behavior. doi:10.1016/j.jvb.2018.05.012

Sung, T. K. (2015). The creative economy in global competition. Technological Forecasting and Social Change, 96, 89-91. doi:10.1016/j.techfore.2015.04.003

van Doorn, S., Heyden, M. L. M., \& Volberda, H. W. (2017). Enhancing Entrepreneurial Orientation in Dynamic Environments: The Interplay between Top Management Team AdviceSeeking and Absorptive Capacity. Long Range Planning, 50(2), 134-144. doi:10.1016/j.lrp.2016.06.003

van Weele, M., van Rijnsoever, F. J., \& Nauta, F. (2017). You can't always get what you want: How entrepreneur's perceived resource needs affect the incubator's assertiveness. Technovation, $\quad 59, \quad 18-33$. doi:10.1016/j.technovation.2016.08.004

Wright, F. (2017). How do entrepreneurs obtain financing? An evaluation of available options and how they fit into the current entrepreneurial ecosystem. Journal of Business \& Finance Librarianship, 22(3-4), 190-200. doi:10.1080/08963568.2017.1372011 